\title{
Business Information Systems Project Success or Failure Factors for an Organization e-Transformation Approaches
}

\author{
Mounir El Khatib, Ph.D \\ Assistant Professor, \\ Information Systems \\ Ajman University of Science \\ and Technology, Ajman, UAE
}

\author{
Riktesh Srivastava, Ph.D \\ Associate Professor, \\ Information Systems \\ Skyline University College, \\ Sharjah, UAE
}

\begin{abstract}
Exhausting the Project Management Work Breakdown Structure (WBS), enactment of business information system in an organizational e-transformation can be noticed as an assortment of Information Systems associated within the business processes. The concern with the aligning business processes with Information Systems always upraised the challenges of success or failures. The study is an attempt to identify various reasons of success or failure of alignment, by considering three factors:

\section{The best enterprise Business Information Systems alignment. \\ 2. The success of each Information Systems project, and \\ 3. The integration and interdependencies of the Information Systems projects}

This paper collects the causes of project success and failure from many means, comprising, list of literatures accessible and finest practices in developing and instigating Information Systems Projects - classified and grouped them, and linked them to Business-IS alignment, to conclude that in most cases the main reasons behind project success or failure is mishandling the project business context.

\section{Keywords:}

Business Information Systems, e-Transformation, Business-IS alignment, Information System Project Management, IS Success Factors, IS Failure Factors.

\section{INTRODUCTION}

The study of Information Systems projects success or failure suggests that there is a critical need for improving the way we manage the projects. The sobering datum is that the surreptitious to an efficacious IS project management has been right in obverse - learning from the past. An Information System Project Management is the critical matter for the organizations due to its high failure rate. The objective of this paper is to lookout the factors of success or failures of information systems project for an organizational etransformation. The factors are not narrowed to any particular industry, rather they do ensue in every country; whether small or large companies; in commercial, non-profitable, and governmental organizations; and without concern to their eminence or reputation. For developing an understanding of the success or failure factors of IS, an in-depth assessment of the obtainable literature has been done. For the study, multiplicity of factors for IS integration with Business process have been taken into account for recognizing the success or failures factors of IS projects.

The study conducted in the research authorizes that not all the failures belong to technical aspects but also to the social aspects of the system. Field ${ }^{[1]}$ illustrates that "projects fail too often because the project scope was not fully appreciated and/or user needs not fully understood." Furthermore, ${ }^{[2]}$ informs that "IS projects and associated procurements take place in an environment characterized by the following:

1. Lack of management continuity, and,

2. An incentive system that encourages overly optimistic estimates of the benefits that can be attained from doing the project.

Leicht ${ }^{[3]}$ in the study confirms that high user expectations can actually be the cause of project failure. A study conducted by Hoffman ${ }^{[4]}$ mentions that projects fail because of poor alignment between IT departments and business users. Hoffman in another study ${ }^{[5]}$ illustrates that project managers too often act as "process cops and report compilers and lose sight of what they're supposed to be doing - to make sure projects are running effectively". Hodgson ${ }^{[6]}$ illustrates that "projects fail - that's the fact of life. Too many fail because the average project is like an iceberg - 9/10ths of it lay hidden from view". In some way or the other, all the urgings are accurate. But none of the study reports systematic research of the apparatuses that source project success or failure. The study conducted in the research weighs 20 factors and 10 factors for the project success and failures correspondingly. Based on feedback from the organizational Transformational strategies, we had devised the mechanism for Business-Information Systems alignment and IS Project Planning Process. The research conducted will deliver an insight for the organizations to deliberate the factors resulting in project failures and provide guidance for the corrective steps. 
The complete paper is planned as follows: Section 2 mentions the Research Methodology espoused for the study. Section 3 exemplifies Business-IS alignment process model. Section 3 expounds about configuration of Business process with Information Systems with prominence on IS Strategic processes. Section 4 demonstrates the Success and Failures factors for any Information Systems projects grounded on the study piloted by Standish group. The segment outlines the 20 and 10 factors correspondingly for challenged/cancelled and successful projects. The section plans the base for the comprehensive study. Section 4 remarks the research outcomes of the study and Section 5 concludes the paper.

\section{RESEARCH METHODOLOGY}

The methodology for the study provides research method(s) is/are appropriate for the development of knowledge in a given study. Due to organization specifics and cultural concepts, in addition to the stated above research challenges, the researcher - in order to be unbiased - had embarked on a combined methodology:

\section{Quantitative Data collection \\ 2. Case Study Analysis}

For the quantitative data collection methods, the instrument used was the random sampling and structured data collection instruments from predetermined response categories. Depending on the questions, we scaled the answers in Likert scale (Ranging from 1-10). The samples was also based on data collection from organizations and situational characteristics in order to statistically control for their influence on the dependent, or outcome, variable.

Typical quantitative data gathering strategies included for the study were:

1. Observing and recording well-defined events

2. Obtaining relevant data from management information systems.

3. Administering surveys with closed-ended questions

Case study analysis provided the direct control over events resulting from direct role and involvement to all selected projects and related documents, and focus on a contemporary phenomenon, making, the details covered not only the decisions taken, but why and how they were taken, and the available alternatives.

Apart from the information gathered from the case studies, there was a need to analyze some organizational aspects which are directly related to the identifications and assessments.

\section{BUSINESS-IS ALIGNMENT PROCESS MODEL}

Throughout the study, it was advantageous to start with moderately transitory understandings of strategic, tactical and operational concept.
Strategically, Business-IS alignment is demarcated by the interactions that occur between the four vital aspects (Business Strategy, IS strategy, Business infrastructure and processes, IS infrastructure and processes) ${ }^{[7],[8]}$. Under this group originates - Constructing the right/wrong effects (business or IS strategy, infrastructure, and processes leadership support - feasibility - analysis and design)

Tactically, Business-IS alignment is defined as relating IS resources in a suitable and appropriate way, in concord with project approaches, goals, and requirements. Under this category emanates- Technical aspects of the project (neglecting the people, culture and processes).

Adams et. al ${ }^{[9]}$ proposed "an operational model that works" contended that organizations that align strategically, without crafting an alignment on an operational level, will be disenchanted with the consequences. They designed an operational model composed of 4 core elements (Governance, Process, Communication, and Metrics) and 3 enablers (Skills, Style, Shared vision). Under this category originates poor project management (methodologies, techniques, capabilities, and processes)

The model proposed in the study assesses all the aforementioned notions and concocts the innovative model for the Business-IS alignment. The architecture of the model is portrayed in Figure 1 is a four-layer model and gage the strategic, tactic and operational facets of the organizational IS requirements. The model follows the cyclic progressions and any procedure can be restructured once the precise BusinessIS alignment is achieved.

\section{IS PROJECTS-FACTORS FOR PROJECT SUCCESS OR FAILURE}

The prominence of the study piloted in the reasearch is to riposte the interrogation "Why do IS projects faunder?". Many of the previous attempts to answer the above question have treated the question from a single point of focus, such as people, techniques, cultures, technology and experience. It was noticed during the exploration that the bigger the project, the more possibility of failure, because, IS project management and its implementation especially is both complex and challenging.

The answer to the question as mentioned by Sue Young ${ }^{[10]}$ "No one disallowed them from waning. We delineate success as a privation of failure and failure as a deficiency of accomplishment. If we exclude the leeway for failure, the only prospect is success. And that requires the definition of success." As eliminating the reasons and possibilities for failure in all the stages of project management, and "building the right things", this implies eliminating the possibility of "building the wrong things". This will lead to defining the critical success factors as those needed to eliminate the key deficiency factors. 


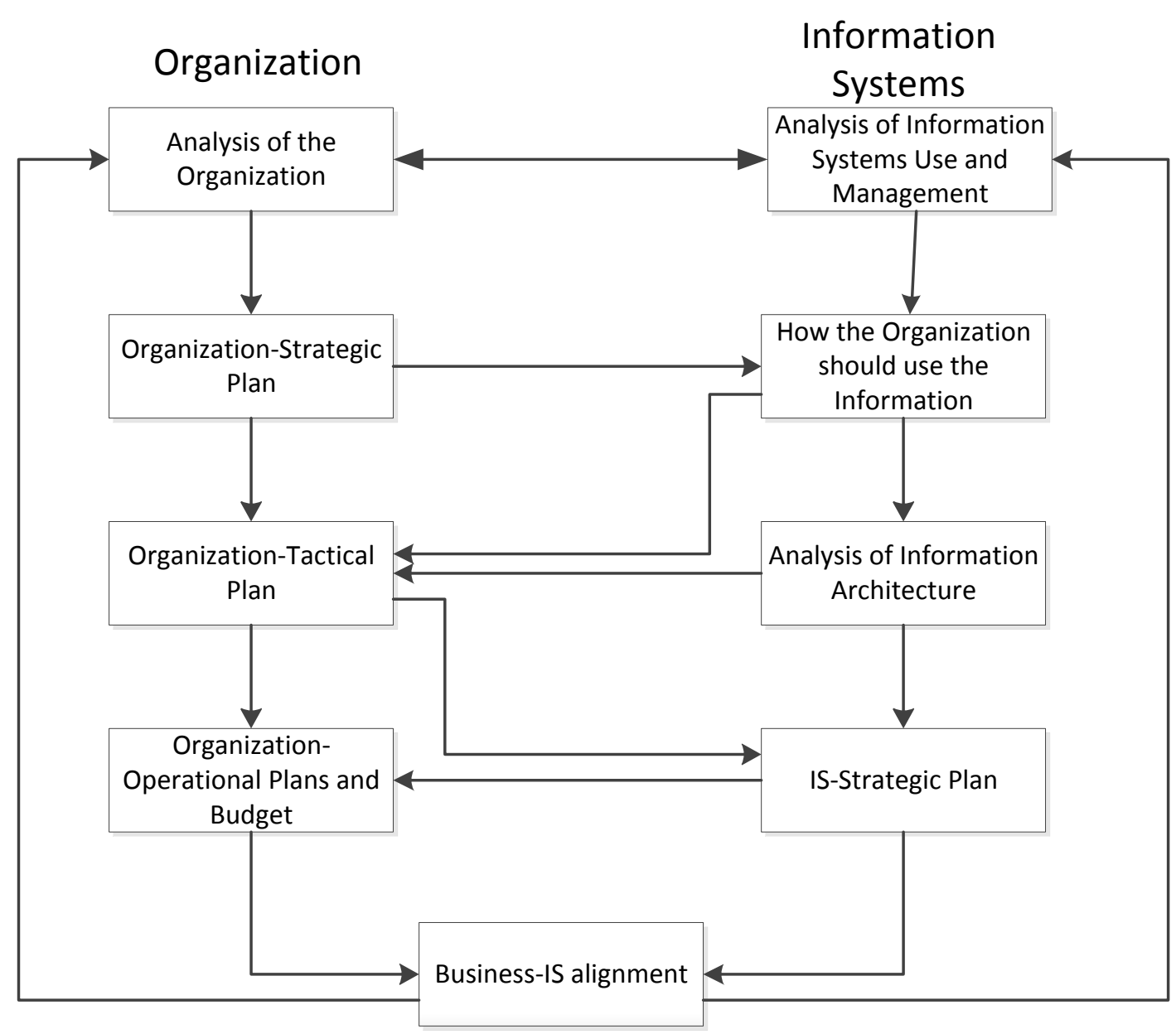

Figure 1: Business-IS alignment model

The strategic part of the model includes three steps, as, indicated in Figure 2 below:

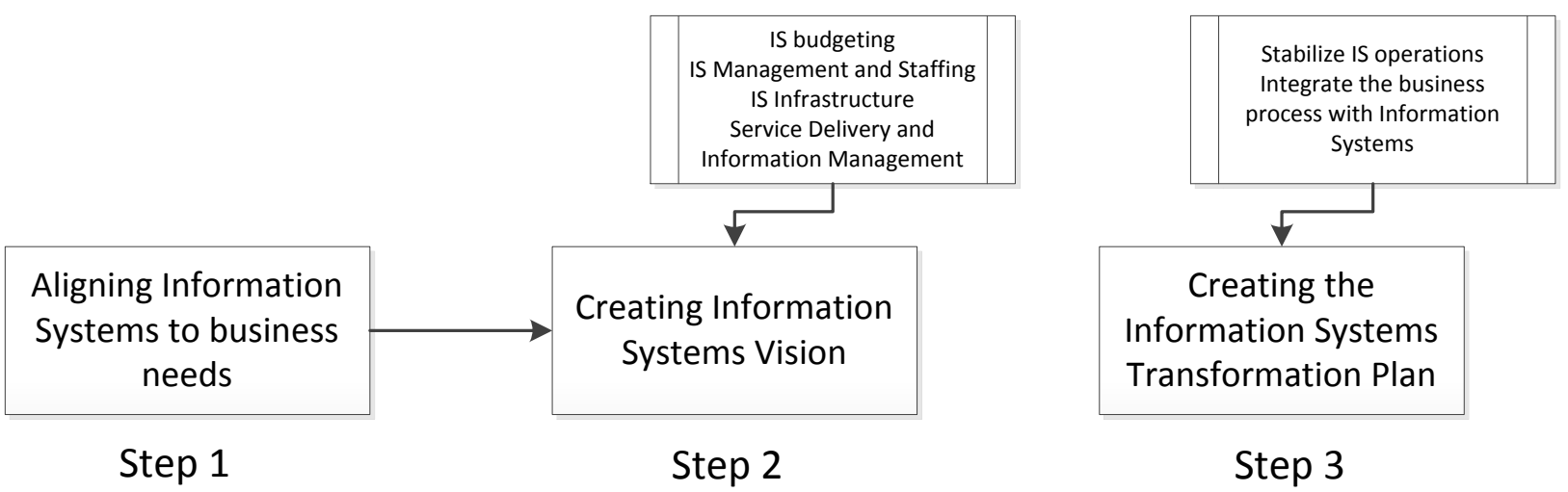

Figure 2: IS strategic planning process

Based on the mentioned explanations, the success or failure of organizational e-transformations depends on the following three factors:
2. The success of each IS project (project management), and

3. The integration and interdependencies of the IS projects

1. The best enterprise business-IS alignment. 


\subsection{IS Projects Failure}

The research is grounded on the Standish group ${ }^{[11]}$ verdicts for challenged and cancelled projects. A project is considered to be botched when it is cancelled, abandoned or not implemented and considered challenged when over budget, behind schedule, or the deliverables are of poor quality or do not meet the original needs of the user or customer. Table 1 gives the comprehensive description of both the challenged and cancelled projects.

Table 1: Standish Group-Factors for Challenged and Cancelled Projects

Lack of user input
Incomplete requirements and specifications
Changing requirements specifications
Lack of executive support
Technology incompetence
Lack of resources
Unrealistic expectations
Unclear objectives
Unrealistic time frames
New technology
Incomplete requirements
Lack of user involvement
Lack of resources
Unrealistic expectations
Lack of executive support
Changing requirements specifications
Lack of planning
Didn't need it any longer
Lack of IT management
Technology illiteracy

It must be noted from the Table 1 that the first 10 factors depicts Projects in Challenged state and the last 10 factors in cancelled state.

\subsection{IS Project Success}

The project management literature commends that there are two apparatuses of project accomplishment ${ }^{[12],[13],[14],[15] \text { : }}$

1. Project success factors: Elements of a project that can be inclined to upsurge the prospect of success; these are independent variables that make success more likely

2. Project success criteria: measures by which we judge the successful outcome of a project; these are dependent variables which measure project success.

Factors to keep in mind in order to ensure system success, according to the ${ }^{[11]}$ findings for succeeded projects, are given in the Table 2.

Table 2: Standish Group-Factors for Projects Success

\begin{tabular}{|c|}
\hline User involvement \\
Executive management support \\
Clear statement of requirements \\
Proper planning \\
Realistic expectations \\
Smaller project milestones \\
Competent staff \\
Ownership \\
Clear vision and objectives \\
Hard working, focused staff \\
\hline
\end{tabular}

\section{Research Outcomes}

The outcomes of the research is grounded on the factors determined by ${ }^{[11]}$ and the responses acknowledged by the organizations ensuing e-transformation phase. The conclusions of the study is alienated into two fragments, specifically, IS projects failure and success factors. Figure 3 depicts the outcomes of the results for projects failures and success (in percentage).

In the study, we also examined that $46 \%$ of the projects are completed and operational, but are over budget, over time estimated, and with less features and functions than originally quantified.

The results of the project success is revealed in Figure 4. 


\section{Issues in Alignment of Business Processes with Information Systems}

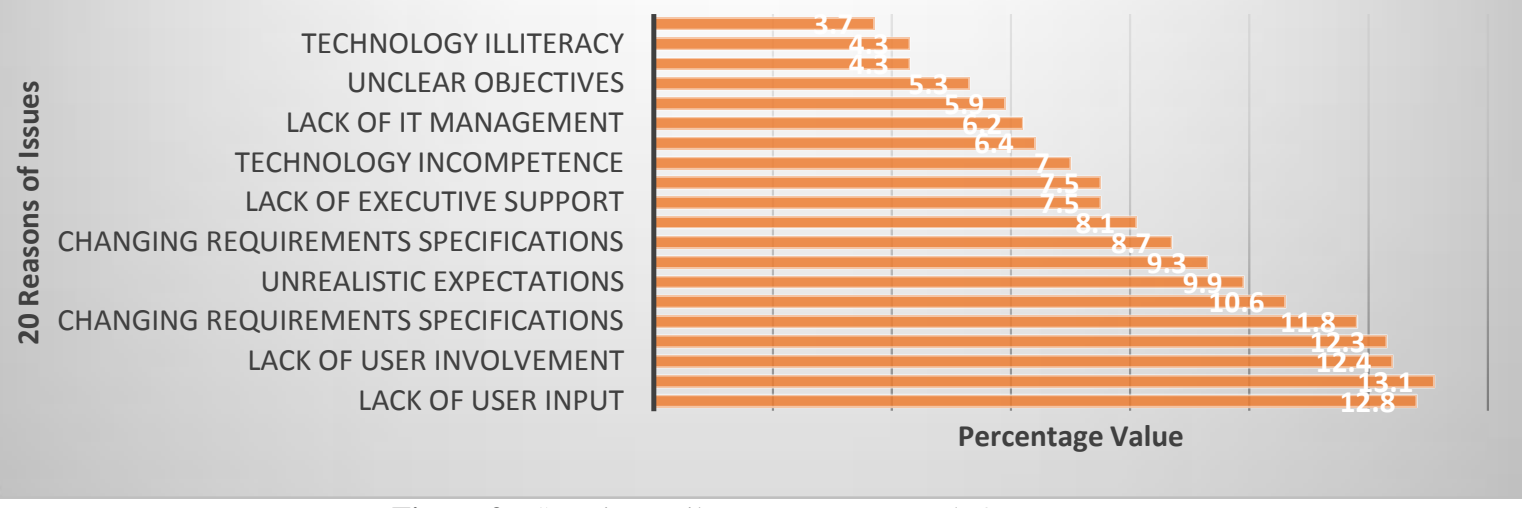

Figure 3: IS Project Failure Factors-Research Outcomes

In the study, we also examined that $46 \%$ of the projects are completed and operational, but are over budget, over time estimated, and with less features and functions than originally quantified. The results of the project success is revealed in Figure 4:

\section{Project Success/Result Analysis}

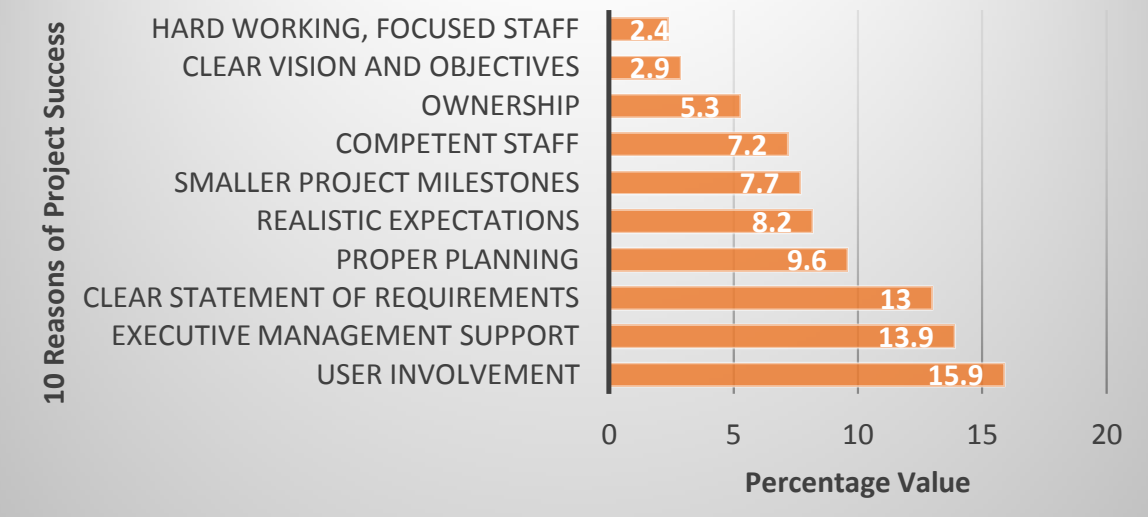

Figure 4: IS Project Success Factors-Research Outcomes

As evidently shown, success of any IS projects depends upon the user participation in the project.

\subsection{Grouping IS Project Success Factors}

On investigation, each of the above 20 reasons can be categorized in three groups, as shown in Figure 5: 


\begin{tabular}{|c|c|}
\hline Group 1 & $\begin{array}{l}\text { Building the wrong things (business or IT strategy, infrastructure, } \\
\text { and processes - leadership support - feasibility - analysis and } \\
\text { design) }\end{array}$ \\
\hline \multicolumn{2}{|r|}{ Reasons: $2,3,4,5,7,8,9,11,15,17,18,20$} \\
\hline Group 2 & $\begin{array}{l}\text { Focusing on the technical side only (neglecting the people, } \\
\text { culture and processes) }\end{array}$ \\
\hline \multicolumn{2}{|r|}{ Reasons: $1,4,7,10,12,17,20$} \\
\hline Group 3 & $\begin{array}{l}\text { Poor Project management (methodologies, techniques, } \\
\text { capabilities, and processes) }\end{array}$ \\
\hline \multicolumn{2}{|r|}{ Reasons: $1,2,3,5,6,9,11,12,15,17,19$} \\
\hline
\end{tabular}

Figure 5: Grouping IS Project Success Factors

As stated in Figure 5, Group 1 and 2 epitomizes the Business-IS alignment in its strategic and tactical form, while Group 3 characterizes the Business-IS alignment in its operational form. It can be also noted that some reasons can descent in more than one category.

\subsection{Grouping IS Project Failure Factors}

For IS Project failure, it's sufficient to have no plan, meanwhile for success we need a sophisticated plan. As with causes for failure, the 10 reasons can be categorized under the subsequent three groups, as specified in Figure 6.

\begin{tabular}{|c|l|}
\hline Group 1 & $\begin{array}{l}\text { Building the right things (business or IT strategy, infrastructure, } \\
\text { and processes - leadership support - feasibility - analysis and } \\
\text { design) }\end{array}$ \\
\hline \multicolumn{1}{|c|}{ Reasons:2, 3, 4, 5, 8, 9 } \\
\hline Group 2 & $\begin{array}{l}\text { Reasons:1 } \\
\text { focusing on the technical side while taking into consideration } \\
\text { that technical projects take place in a broader context (people, } \\
\text { culture and processes) }\end{array}$ \\
\hline Group 3 & $\begin{array}{l}\text { Solid Project management (body of knowledge, methodologies, } \\
\text { techniques, capabilities, and processes) }\end{array}$ \\
\hline & \begin{tabular}{l} 
Reasons:3, 4, 6, 7, 10 \\
\hline
\end{tabular} \\
\hline
\end{tabular}

Figure 6: Grouping IS Project Failure Factors

As stated in Figure 6, Groups 1 and 2 represent the business-IT alignment in its strategic and tactical form, while group 3 represents the business-IT alignment in its operational form. It can be also noted that some reasons can descent in more than one category.

\subsection{IS Project requirements-To achieve the needs?}

In addition to the three settings cited, scrutiny of the causes that regulate the IS project success or failure was revealed by ${ }^{[16]}$, who debuted the 3 Key necessities to all IS Project

Success that all successful projects have in common, "Each project can be viewed as a tripod. All three legs must be in place for the tripod to stand sturdily. In a systems project, these "legs" or critical success factors consist of the following:

Base one: Top management support (fulfill the business/IS strategy on organizational and operational level).

Base two: A sound methodology (effective and entrepreneurial).

Base three: Solid technical leadership by someone who has successfully completed a similar project. 
Point noteworthy here is that base 1 and 2 represent the business-IS alignment in its strategic and tactical form, while base 3 represents the business-IS alignment in its operational form.

Deprived of these sturdily in place, the "tripod" will tumble and the project will faunder. It was also noted that asserting on keeping costs stumpy and rushing the project along, the quality will be low or the risk of failure will be high, no matter how fine the project is accomplished.

\subsection{Project and program management}

Glenn Kessler ${ }^{[17]}$ updated three inevitable essential Project Management Principles as:

Principle one: Context Principle: Technical projects take place in a broader context.

With this principle there is a clear consideration and focus on the external environment, stakeholders, customer, markets, adequate users, and executive leadership (business-IS alignment)

Principle two: Entropy Principle: The amount of disorder in projects will not, of itself, decrease with time

- This will happen only if a project continues to develop on right basis

- The disorder Key Process Areas are

- Requirements Management

- Software Project Planning

- Software Project Tracking and Oversight

- Software Subcontract Management

- Software Quality Assurance

- Software Configuration Management

Principle three: Society Principle: Technical projects are also social undertakings

In the specified project management principles, Principle 1 and 3 denote the business-IS alignment in its strategic and tactical form, while principle 2 characterizes the business-IS alignment in its operational form.

\section{CONCLUSION}

Failing of any IS project specifies that the project has no aptitude or competence to accomplish its purposes and has failed to triumph one or more of its CSF's. CSF's are the aspects which plump the success or failure of any IS project and success depends on the attainment of the intentions of these facets. A successful project must not only mechanize procedures but also mend business assessment, customer service, provides competitive advantage and thereby produces a quantifiable bearing on the bottom line through qualitative and quantitative aids. The end result of the project must gratify or surpass the novel necessities of the stakeholders.

\section{REFERENCES}

[1] Field, Tom, When bad things happen to good projects", CIO magazine, Vol. 11, No. 2; pp. 54-60, 1997.
[2] Hulme, Martyn R.,"Procurement Reform and MIS Project Success", Journal of Supply Chain Management, Vol. 33, No. 1, 1997.

[3] Leicht, Michael, "Managing User Expectations." University of Missouri St. Louis e-publication, http://www.umsl.edu/ sauter/analysis/user_expectations. html, 2003.

[4] Hoffman, Thomas, "Corporate Execs Try New Ways to Align IT with Business Units." Computerworld. http://www.computerworld.co m/printthis/2003/0,4814,86466,00.html, 2003.

[5] Hoffman, Thomas "Value of Project Management Offices Questioned", Computerworld, http://www.computerworld.com/printthis/2003.0,4814,82 345,00.html, 2003.

[6] Hodgson, Ian, "Keeping Your Head Above Water", http://www/conspectus.com/2002/november/article19.as p, 2002.

[7] Luftman, Jerry, "Competing in the Information Age: Align in the Sand", Oxford University Press and Luftman, Jerry, "Managing the IT Resource", Prentice Hall, New York, 2003

[8] Henderson and Ventkatraman, "Strategic Alignment: Leveraging Information Technology for Transforming Organizations", IBM Systems Journal, Vol. 32 No. 1, 1993.

[9] R. Adams, D.Wong, D. Latimore, "Business and IT operational models in financial services: beyond strategic alignment", IBM business consulting services, www.ibm.com/bcs.

[10] Young S, "Why IT projects fail: There's a difference between managing risk and preventing failure", 2003.

[11] Standish Group, "Report on IT Application Development", 2002.

[12] Jugdev, K. and Muller, R., “A retrospective look at our evolving understanding of project success. Project Management Journal Vol. 36 No. 4, pp. 19-31, 2005.

[13] Morris, P.W.G. and Hough, G.H., "The Anatomy of Major Projects: A Study of the Reality of Project Management. John Wiley \& Sons, Ltd., Chichester, UK, 1987.

[14] Wateridge, J.. "How can IS/IT projects be measured for success?. International Journal of Project Management Vol. 16 No. 1, pp. 59-63, 1998.

[15] Turner, J.R., "Handbook of Project-based Management: Improving the Process for Achieving Strategic Objectives.(2nd ed.). McGraw-Hill, London.

[16] Dorsey P, "Why large IT projects fail, http://dulcian.com/three-more-reasons-why-softwareprojects-fail, 2013.

[17]GlennP.Kessler,http://www.cs.hmc.edu/ mike/courses/mi ke121/readings/intro/Kessler.pdf 